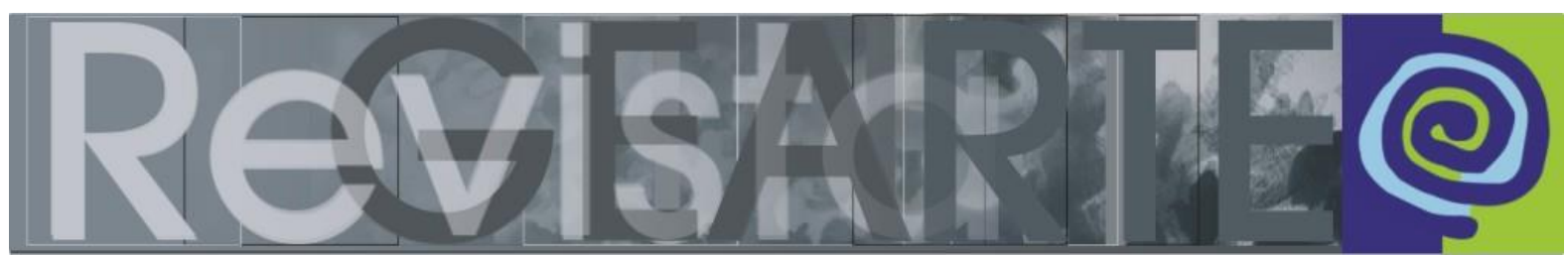

ISSN 2357-9854

\title{
Imagens e sentidos: do preenchimento do vazio ao transbordamento
}

\author{
Cláudia Aparecida dos Santos (Universidade Federal de Santa Maria - UFSM, \\ Santa Maria/RS, Brasil)
}

RESUMO - Imagens e sentidos: do preenchimento do vazio ao transbordamento - Este artigo busca compreender aspectos da natureza sígnica das imagens, mormente o que estas oferecem em termos de construção de sentidos para os sujeitos e para as culturas. A análise discute e trata as imagens não apenas pelo seu valor estético, mas, entende as imagens como potências que movimentam o cenário da contemporaneidade, em face do reconhecimento da multiplicidade de artefatos visuais que compõem o cenário atual compreende, que, constituem as imagens significativos lugares de aprender. A construção teórica é desenvolvida na perspectiva da Cultura Visual, por reconhecer este campo de conhecimento como sendo capaz de dar conta, ao menos em parte, dos estudos das imagens, das mídias, bem como do complexo campo visual. Por fim, a discussão almeja colaborar para a qualificação da recepção da cultura da imagem como participe dos processos formativos que acontecem também fora das salas de aula. Sobretudo, o faz, por entender as imagens como componentes imprescindíveis dos saberes.

PALAVRAS-CHAVE

Imagem. Educação. Cultura Visual. Contemporaneidade.

ABSTRACT - This article seeks to understand aspects of the signic nature of images, especially what they offer in terms of the construction of meanings for subjects and for cultures. The analysis discusses and treats the images not only for their aesthetic value, but, understands the images as powers, that move the contemporary scene, in the face of the recognition of the multiplicity of visual artifacts that compose the present scenario comprises, that constitute the images Places of learning. Theoretical construction is developed from the perspective of Visual Culture, since it recognizes this field of knowledge as being able to account, at least in part, for studies of images, media, and the complex visual field. Finally, the discussion aims to collaborate to qualify the reception of image culture as it participates in the formative processes that also happen outside the classrooms. Above all, it does so by understanding images as essential components of knowledge.

KEYWORDS

Image. Education. Visual Culture. Contemporaneity.

\section{Primeiro disparo: [...] do preenchimento do vazio}

O movimento gerado pela potência do ver nas últimas décadas altera as dinâmicas que escrevem o andamento da vida na cotidianidade. Os novos hábitos, relacionados à produção e usos das imagens, deflagram a urgência de seu enfrentamento.

De antemão, quero dizer que as imagens centralizam modos de expressão, formas de comunicação e autorreferência, no passado remoto e ainda hoje. No 
entanto, é manifesto que nas últimas décadas, dada a ampliação dos meios tecnológicos e midiáticos, alastram-se como aportes ao andamento das dinâmicas e contornos culturais.

É necessário sublinhar que as imagens aqui mencionadas são, sem margens para exceções, fruto da criação humana, produzidas como um meio de expressão e, sobretudo, perspectivadas como aparatos culturais de comunicação. Parto de uma ideia presente em Elkins (2001), segundo o qual as imagens são "artefatos visuais" e não surgem de maneiras autônomas. Portanto, são o resultado consciente de uma ação humana.

Pois bem, aceitar que as imagens se vinculam às composições identitárias, particulares e coletivas, seja em níveis superficiais ou mais aprofundados, sendo determinantes do que vemos e como queremos ser vistos, leva-me a ponderar com maior cautela o lugar das imagens nas culturas humanas na atualidade.

Cabe assinalar o crescente número os estudos que se debruçam sobre a temática, incluindo importantes áreas do conhecimento humano. Como exemplo, podemos mencionar a semiótica, antropologia visual, cultura visual, história da arte, estética etc. ${ }^{1}$. No entanto, devido à imprecisão conceitual, dada a amplitude e diversidade com que o conceito de "imagem" tem sido utilizado, há grandes dificuldades de definições, classificações ou até mesmo de entendimento sobre a presença das imagens nas culturas.

De fato, "[...] embora tenhamos milhares de palavras sobre as imagens, ainda não temos uma teoria satisfatória sobre elas", como assinala Mitchell (2009, p. 17).

Aliás, apesar de não haver uma única teoria capaz de responder sobre o que são realmente as imagens ou, como elas afetam os sujeitos, os estudos que atentam para o assunto, mesmo que, por vezes, difundidos por um amplo conjunto de

1 Logicamente, e a despeito do seu potencial, estes estudos ainda são poucos se comparados com o extenso número de pesquisas sobre a natureza, estruturas e funções das interações verbais humanas (SANTAELLA \& NÖTH, 2001). No entanto, o que se evidencia é que os estudos voltados ao campo visual estão ganhando legitimidade como campo teórico, nas últimas décadas. 
disciplinas e teorias ajudam ou, ao menos, oferecem pistas para o aclaramento da matéria.

O assunto é vasto. Não por acaso estudiosos como Debray (1993) e Santaella \& Nöth (2001), estimam que a comunicação visual teria seu início, junto à espécie humana, antes mesmo das primeiras amostras de comunicação verbal, podendo, até mesmo, ter contribuído para o surgimento e consolidação desta.

Na contemporaneidade a comunicação visual firma-se como uma das formas de interação social mais utilizadas. Consequentemente, tamanha profusão imagética, como um acontecimento amplamente generalizado confere um novo formato às sociedades, culminando em uma forma de comunicação heterogênea e ressignificada.

Destarte, estão presentes nas culturas mais do que em qualquer outro momento da história. E, em muitos aspectos, subsidiam as acepções de paradigmas que caracterizam a atualidade (MIRZOEFF, 2003). Vale lembrar que com o advento da revolução industrial, da cultura de massa, a reprodutibilidade técnica de que trata Walter Benjamin (1986), e a terceira globalização, intensificam-se os meios de interação propiciados pelo visual.

No entanto, as retóricas e interpretações que circundam sobre a feitura, disseminação e apropriação das imagens são bastante complexas. Paradoxalmente têm-se as imagens muito presentes em nosso cotidiano, e essa facúndia com que se mostram, contribui para torná-las, muitas vezes, apenas banais.

Outros exemplos de descaso frente às imagens podem ser notados nas apropriações que submetem as imagens à linguagem tradicional como sendo meras ilustrações. Trata-se de renitentes formas de leituras reducionistas, inoperantes e impotentes frente à crença do poder transcendental muitas vezes conferido às imagens, sua aura indecifrável, sua mistificação ou, ainda, leituras que se acomodam na inércia ao considerar o caráter fixo e naturalizado das imagens.

O fato é que na contemporaneidade, ainda teima em permanecer, leituras reducionistas e ineficazes ao enfrentamento e a recorrente banalização das imagens, 
evidenciadas no descaso e irresponsabilidade acerca da produção, circulação e assimilação destas mesmas imagens pelo mercado.

O fato é que estas leituras que de longa data acompanham as imagens, inibem o avanço e aproximações mais perspicazes acerca da sua presença na formação dos sujeitos e das culturas como um campo de conhecimento significativo. Contemporaneamente, o conceito de imagem tem sido quase que exclusivamente associado à natureza midiática das culturas globalizadas. Ora caracterizadas como artefatos de dominação e controle, ora debeladas por sua aparente naturalidade. Tais leituras constituem um sério problema na medida em que se mostram ineficazes ao enfrentamento das imagens na atualidade.

Mitchell, em Teoría de la imagen (2009), compreende a imagem como uma categoria imprescindível às ciências humanas. Para o autor, as imagens se situam na metade do caminho entre o que Thomas Kuhn chamou paradigma e uma anomalia, não sendo possível saber o que ela realmente é. Constituindo um problema a se resolver (MITCHELL, 2009, p. 21).

Contudo, se não é possível afirmar o que são as imagens, outras indagações podem ajudar a entender como elas afetam os sujeitos. Julgo, assim, relevante uma aproximação do conceito de imagem num sentido mais amplo.

Autores como Debray (1993) Santaella \& Nöth, (2001), Joly (1994) debruçamse sobre o tema e fazem apontamentos importantes que podem contribuir para o entendimento que pretendo: apreender as imagens para além de seus contornos, cores e formas e incluí-las como potentes "lugares do aprender".

Os estudos realizados oferecem, em grande parte, análises que permitem considerá-las consonantes entre si, sobretudo quando se aproximam das origens das imagens. Segundo os autores citados, ao se perseguir a raiz do termo imagem, chegase as três origens possíveis, são elas; eikón, éidolon e imago. 
O primeiro pertencente à filosofia antiga, eikón (daí deriva a palavra ícone, na acepção que the conferimos, em língua portuguesa $)^{2}$. O termo surgiu para designar diversos tipos de imagens visuais naturais, por exemplo, sombras, vultos e reflexos. Compreende também as imagens artificiais, pinturas artísticas, desenhos etc. Inclusive as imagens não-visuais, como as palavras e as ideias.

A segunda origem encontrada da palavra imagem surge na Grécia antiga, éidolon, (ídolo, em grego), expressava mais acertadamente a imagem "espectral" de uma pessoa, viva ou morta. (JOLY,1994; SANTAELLA \& NÖTH, 2001). Neste caso, o termo imagem está relacionado a ídolo. Em grego éidolon "que significa fantasma dos mortos, espectro, e, somente em seguida, imagem, retrato" (DEBRAY, 1993, p. 24).

Já a raiz etimológica da palavra imagem, tal qual a conhecemos, pode ser coligada a palavra imago, do latim, que fez derivar imaginem, depois imagine e, finalmente, no português, "imagem" e quer dizer representação. Na Roma antiga, imago era o nome que recebiam as mascaras mortuárias em cera ou gesso (DEBRAY, 1993, p. 24).

Contudo, seu valor também é polissêmico. Além da ramificação das fontes etimológicas, o conceito de imagem pode ser vinculado a diferentes sentidos e áreas. Possui aplicação na ciência (imagens via satélites, infravermelhas, ultra-som etc.), na estética, na moda, na publicidade (imagens televisivas, jornalísticas etc.), na antropologia visual, na arte (esculturas, desenhos, pinturas), nos imaginários etc. (SANTAELLA \& NÖTH, 2001).

Ao longo dos tempos, as imagens foram marcadas com o estigma de personalidades, míticas, sagradas, mágicas, perversas, enganadoras, manipuladoras, contemplativas, guardiãs da beleza e do sagrado etc. São algumas das definições ou adjetivações que expressam os "poderes" que se conferiram às imagens.

2 Eikón, em grego significa: imagem, retrato, estátua, segundo o vocabulário encontrável em MURACHCO, Henrique. Língua grega: visão semântica, lógica, orgânica e funcional. v. 2 (2003). Por extensão, pode significar também, semelhança ou algo que se assemelha. Em alguns casos é traduzido por símile, derivação de semelhante. 
A este respeito, é crucial, apesar de tamanha volubilidade de sentidos, demarcar com firmeza que até o momento o que não deixa dúvida é sua função sígnica, pois que as imagens sempre se mostraram como algo que está relacionado à outra coisa distinta delas próprias, porém densamente intrincadas com feitos e saberes humanos.

Debray traz um exemplo que pode aclarar a afirmação acima. $O$ autor conta que "nos ritos medievais o corpo do rei morto deveria ficar exposto durante quarenta dias", o que na época não era possível. Para tanto, utilizava-se uma réplica, uma figura, que em trajes reais era reverenciada representando o rei ausente (DEBRAY, 1993, p. 23). Quero explicar que o que a imagem representava não estava na silhueta em si, para além das formas e volumes que os súditos viam. O que importava era seu valor sígnico. Durante esse período de quarenta dias o novo rei a tomar posse deveria permanecer em segundo plano, pois a imagem reinava em unanimidade.

Outro exemplo dado por Mitchell e que facilmente pode ser compreendido pela proximidade com o cotidiano de qualquer um, instiga de antemão a tentar entender onde estaria o "poder" das imagens. Quando o autor problematiza que "[...] todo mundo sabe que a fotografia de sua mãe não está viva, mas ainda assim serão relutantes em desfigurá-la ou destruí-la", leva a perguntar em que se sustenta a relação do visível com o significado que damos a este. O autor continua, afirmando que não há pessoa racional que pense que as imagens devam ser tratadas como pessoas, "[...] mas parece que sempre estamos dispostos a fazer exceções em casos especiais" (MITCHELL, 2014, p. 11, tradução nossa).

O exemplo acima por sua simplicidade análoga ao cotidiano confere uma facilidade de acesso ao que o autor perspectiva. Parece óbvio que convidar um indivíduo a rasgar, destruir a foto de sua mãe amada lhe acarretaria uma espécie de sofrimento. A questão, contudo, está no porquê a imagem impressa em um papel pode causar sofrimento, e por que destruir tal imagem é provocar no sujeito uma perda.

Os apontamentos supracitados podem ser explicados aqui de modo simples, pois versam sobre a adequabilidade gerada a partir do visível e do simbólico, o 
encontro sujeito e imagem suscita um tipo de "simbiose" compondo deste uma imagem única em cada sujeito que vê. Esta é sua particularidade.

Encontro em Mitchell uma inquietante afirmação, que pode ajudar ao entendimento deste pensamento, quando o autor diz "[...] os espectadores se deixam seduzir pelas imagens", pois elas guardam em si o "[...] poder de fazer retornar aos que vêem parte daquilo que ele é" (p. 48). Nos termos da análise de Mitchell, a imagem mostra o que o espectador deseja ver. Nas palavras do autor seria como "[...] uma espécie de espelho para o espectador" (MITCHELL, 2005, p. 48).

Claro que, por consequência, as infinitas simbioses possíveis impedem desvendar completamente as formas pelas quais as imagens passam pelos que as vêem, mas não impedem de pensar sobre elas.

\section{[...] do transbordamento}

A emergência do fenômeno da visualidade a componente cultural, significativo para a produção e consolidação dos novos paradigmas que circunscrevem nosso tempo reforça a justificativa do por que pensar as imagens como lugares do aprender. Visto que elas medeiam às relações de crianças, adolescentes e mesmo adultos com os saberes, inaugurando novas expressões de subjetividade firmando-se como componentes qualitativos para a formação por constituírem referência para os sujeitos ${ }^{3}$.

O fato é que a concretização do mundo globalizado se dá cada vez mais centralizada no olhar. O presente se escreve num movimento de rupturas, e este novo formato, embora não fixo, admite mudanças nas formas de ver o mundo e se mostrar ao mundo. As imagens, na atualidade aparecem como um dos principais veículos da comunicação humana, já não se "[...] limitam a servir de marcadores para objetos que

3 A noção de subjetividade aqui evocada apóia-se em Félix Guattari e Suely Rolnik, para quem a subjetividade "[...] resulta de um entrecruzamento de determinações coletivas de várias espécies, não só sociais, mas econômicas, tecnológicas, de mídia, etc." (1996, p. 34). 
Ihes sejam anteriores [...]", mas, muito mais que isto, "[...] criam sentidos" (SILVA, 1999, p. 44).

Pode-se dizer que a partir da elevação do visual ao plano de fenômeno cultural, algumas mudanças de hábitos passaram a vigorar e, por sua vez, a subsidiar o surgimento também de um novo sujeito de conhecimento. Penso assim, que frente à complexificação dos processos cognitivos agenciados pelo olhar, a problemática da visualidade, que envolve as imagens como espaços ativos e efetivos de formação passa a ser uma discussão urgente. Bem como um convite para assentir as experiências visuais como parte imprescindível do processo formativo que acontece mediado por imagens.

Tal quadro traz as imagens para o centro da discussão, ora analisadas como produto, ora como protutoras das mudanças de paradigmas que caracterizam a atualidade. Pode-se dizer que as imagens, de modo geral, habitam os sujeitos e, apartir de então, medeiam o relacionamento deste com o mundo, com os demais individuos da cultura e consigo próprios. São, antes de qualquer outra coisa, forças simbióticas comunicantes.

Insisto em asseverar que a recepção das imagens como parte dos saberes, se trata de um caminho imprescindível de ser percorrido, uma vez que as imagens se firmam como componentes culturais relevantes na atualidade, sobretudo se considerarmos uma educação para além das velhas barreiras educacionais que teima em aprisionar o conhecimento em quatro paredes. Basta ver este novo sujeito de conhecimento que vem, e que se compõe tanto verbalmente quanto visualmente ${ }^{5}$.

Os abrigos de identidades provisórias acontecem modiados por imagens, quer sejam artísticas, publicitárias, anônimas, jornalísticas, pornográficas, voltadas ao consumo, ao fetichismo, à religião, etc., que oferecem constantemente papéis a

4 Segundo Martin Jay por "sentidos" se compreende "não apenas aos dotes corpóreos naturais que nos permitem acessar o mundo, mas também aos significados que atribuímos aos resultados deste contato" (2012, p. 3).

5 Não julgo, contudo, que a visão e a linguagem oral sejam os únicos meios de troca dos sujeitos com o mundo. Considero, sim, os demais sentidos. Os sujeitos se compões na complexidade das experiências humanas, e trocas com o mundo, se inscrevem corporalmente, olfativamente, etc. Contudo, esta seria uma discussão muito longa para desenvolvê-la a contento aqui. 
desempenhar e modelos a seguir, apresentam objetos e objetivos a alcançar. Quer seja ao anunciarem a roupa ideal, o cabelo que devemos e gostariamos de ter, definindo assim, mesmo que provisóriamente, quem gostariamos de ser.

Posto de outro modo é inegável que muito das referências de crianças, jovens e mesmo adultos advêm das fontes visuais; muitas vezes longe da realidade dos museus, externas ao contexto escolar, familiar ou até mesmo cultural, dito assim no singular. Pasteurizam-se também as imagens dominantes da cultura globalizada ${ }^{6}$.

Portanto, atento para o fato de que já há algumas décadas as perspectivas que se põem como formadoras de opiniões, condensadoras de olhares, são ditadas por uma nova forma de poder que se estabelece. Capaz de ressignificar olhares e maneiras de interpretar o mundo?.

A este respeito Mitchell propõe a visão qualificada como construção cultural. Assevera:

[...] a visão e as imagens visuais, as quais (para os novatos) são aparentemente automáticas, transparentes e naturais; na verdade são construções simbólicas; como uma linguagem a ser aprendida, um sistema de códigos que interpõem um véu ideológico entre nós e o mundo real (MITCHELL, 2003, p. 237).

Tal leitura tem ressonância na voz de Foucault, que embora não tenha analisado especificamente o campo visual, e sim se dedicado às tramas do poder/saber, empresta seus estudos ao campo visual que a partir dele entende a visualidade como aparelhamento de comunicação e expressão configurado como construto social, produzido, anunciado e aceito.

Naturalmente, em uma época de vastas possibilidades técnicas, eclode a exacerbação imagética, na qual, os diversos mídias visuais materializam-se como

6 De acordo com Rolnik, por ainda estarmos um tanto distraídos "[...] o que vislumbramos da subjetividade é o perfil de um modo de ser - de pensar, de agir, de sonhar, de amar etc. - que recorta o espaço, formando um interior e um exterior [...] Isso nos faz pensar que este perfil é imutável, assim como o interior e o exterior que ele separa" (1997, p. 1).

7 Tomo a palavra "poder" na acepção que me confere Michel Foucault na obra Microfísica do poder (1979). Contudo, não pretendo dar conta de sua discussão sobre o saber ou o poder, apesar de estes conceitos apresentarem-se indissociáveis à discussão que desenvolvo sobre as imagens como elemento problematizador na pós-modernidade. 
lugares privilegiados de pedagogização do olhar, onde os indivíduos se espelham, se reconhecem, sociabilizam, e não poucas vezes são a principal fonte de orientação.

Por esta concepção, o campo visual é dado como um fenômeno de ampla importância na contemporaneidade, mediante o impacto que gera. De fato, os medias visuais atualmente abarcam sistematicamente grande parte das culturas. Sendo assim, ceder lugar para a formação visual inicia por recepcionar as imagens como forma de expressão e comunicação importantes ao desenvolvimento dos sujeitos.

Não obstante, entendo que falar sobre a educação do visual mais do que uma preocupação específica da educação formal, que em muitos casos ainda se mostra omissa a este respeito, torna-se uma necessidade em todas as esferas da vida. Pois tal discussão é componente obrigatório no que tange a formação integral dos sujeitos. Pensar a formação visual para além das salas de aula, em tempos-espaço do ócio, trata-se de dar uma oportuna resposta a uma problemática do presente.

Inegavelmente o olhar tornou-se um respeitável mediador de experiências e conhecimentos, e isto impele considerar as imagens como elementos compositivos dos sujeitos e das culturas na atualidade. Já que muito das construções subjetivas, identitárias e de sensibilidades podem ser subtraidas das imagens dominantes da cultura globalizada.

O meio visual compõe uma importante área de formação de homens e mulheres. De tal modo, problematizar os meios midiáticos e tecnológicos, como programas de TV, sites de relacionamentos, performances em shows, corpos de modelos expostos em outdoors, imagens jornalísticas, publicitárias, artísticas, etc., torna-se imprescindivel. Pensar uma formação possível a partir dos lugares onde os sujeitos encontram suas referências.

Portanto se faz cogente repensar os modos como coexistimos com esta infinidade de imagens que nos passam e comunicam aos nossos desejos. Aliás, cabe sublinhar que as novas funções das imagens no cotidiano afiançam a consolidação do mundo que acontece "visualmente orientado", e tal fato exige reelaborar as formas de enfrentamento e recepção do campo visual (SAUNDERS, 1984). 
Concordo com Raimundo Martins quando enfatiza que o enfrentamento que o campo visual exige, na atualidade, só pode ser alcançado se pensado para "[...] além de um repertório de eventos ou objetos visíveis porque pressupõe uma compreensão dos seus processos, o modo como operam, suas implicações e, principalmente, seus contextos" (MARTINS, 2009a, p. 35).

O anunciado corrobora para o entendimento de que o ver se dá num movimento muito mais complexo do que se imaginou durante muito tempo. "Nessa perspectiva, artefatos culturais e artísticos são compreendidos como formas de narrar ou mencionar vivências, cotidianos e posicionamentos, caracterizando grupos de sujeitos, conceitos, valores e subjetividades" (OLIVEIRA \& PAZ, 2012, p. 3).

Oliveira e Paz reforçam a ideia de que o visual não pode continuar a ser tomado como um subproduto derivado da realidade social, cuja função se restrinja a representar discursos verbais ou imitar a realidade, mas, sim, deve ser entendido como um componente ativo "[...] vistas, dessa forma, não como um espelho da realidade, mas como maneiras de mediar a produção de sentidos" (OLIVEIRA \& PAZ, 2012, p. 3). Compostas por intensas tramas e ligações que também interferem, preenchem a vida e apresentam a realidade.

A meu ver o momento é propício para anunciar uma aproximação entre a educação e as experiências visuais cotidianas de modo significativo para o processo formativo. $E$ isto não será possível, simplesmente, ao aferir o uso das imagens como bom ou ruim. Mas, para além disso, trata-se necessariamente de subsumir as imagens como parte constitutiva dos sujeitos e das culturas, parte da própria linguagem, parte dos saberes, capaz de mobilizar a realidade subjetiva, social e histórica vinculadas às práticas do ver.

\section{Referências}

AGAMBEN, Giorgio. O que é o contemporâneo? e outros ensaios. Chapecó: Argos Editora, 2009. AGAMBEN, Giorgio. Profanações. São Paulo: Editora Boitempo, 2007.

AUMONT, Jacques. A imagem. Campinas: Papirus, 2002.

BAUMAN, Zygmunt. Vida para o consumo: a transformação das pessoas em mercadoria. Rio de Janeiro: Zahar, 2008.

BAUMAN, Zygmunt. Vida líquida. Rio de Janeiro: Zahar, 2007. 
BAUMAN, Zygmunt. Identidade. Rio de Janeiro: Zahar, 2005.

BAUMAN, Zygmunt. Globalização: as consequências humanas. São Paulo: Zahar, 1999.

BENJAMIN, Walter. A obra de arte na era da sua reprodutibilidade técnica. In: BENJAMIN, Walter. Obras escolhidas: magia e técnica, arte e política. São Paulo: Brasiliense, 1986.

DEBORD Guy. A sociedade do espetáculo. Rio de Janeiro: Contraponto, 2003.

DEBRAY, Regis. Vida e morte da imagem: uma história do olhar no ocidente. Petrópolis: Vozes, 1993.

DELEUZE, Gilles. Foucault. São Paulo: Brasiliense, 2005.

DELEUZE, Gilles; GUATTARI, Félix. Mil platôs: capitalismo e esquizofrenia. São Paulo: Ed. 34, 1996.

ELKINS, James. História da arte e imagens que não são arte. Revista Porto Arte: Porto Alegre, v. 18, n. 30, maio/2011 Disponível em: <http://www.seer.ufrgs.br/PortoArte/article/viewFile/29619/18306>. Acesso em: 02 maio 2015.

ELKINS, James. The domain of images. Ithaca: Cornell University Press, 2001.

FOUCAULT, Michel. Outros espaços. In: FOUCAULT, Michel. Ditos e escritos. Rio de Janeiro: Forense, 1984. p. 411-422.

FOUCAULT, Michel. História da sexualidade I: a vontade de saber. Rio de Janeiro: Graal, 1999.

FOUCAULT, Michel. Sobre a história da sexualidade. In: FOUCAULT, Michel. Microfísica do poder. Rio de Janeiro: Graal, 2000.

FOUCAULT, Michel. Vigiar e punir: nascimento da prisão. Petrópolis: Vozes, 2006. Disponível em: <http://www.uesb.br/eventos/pensarcomfoucault/leituras/outros-espacos.pdf>. Acesso em: 02 maio 2015.

FOUCAULT, Michel. Microfísica do poder. Rio de Janeiro: Graal, 1979.

GUATTARI, Félix; ROLNIK, Suely. Micropolítica: cartografias do desejo. Petrópolis: Vozes, 1996.

HERNÁNDEZ, Fernando. La necesidad de repensar la educación de las artes visuales y su fundamentación en los estudios de cultura visual. Seminário proferido no Congreso lbéricode Arte Educación. Porto, Portugal, nov. 2001. Disponível em: <http://www.rio.rj.gov.br>. Acesso em: 02 maio 2015.

HERNÁNDEZ, Fernando. Catadores da cultura visual: proposta para uma nova narrativa educacional. Porto Alegre: Mediação, 2007.

JOLY, Martine. Introdução à análise da imagem. Lisboa: Edições 70, 1994.

MARTINS, Raimundo. Cultura visual: imagem, subjetividade e cotidiano. In: MEDEIROS, Maria Beatriz de (Org.). Arte em pesquisa: especificidades. Brasília: Editora da Pós-Graduação em Arte da Universidade de Brasília (UnB), v. 2, 2004. Ensino e Aprendizagem da Arte. p. 160-166.

MARTINS, Raimundo. Hipervisualização e territorialização: questões da cultura visual. Educação \& Linguagem, v. 13 n. 22, p.19-31, jul./dez. 2010.

MARTINS, Raimundo; TOURINHO, Irene (Orgs.). Educação da cultura visual: conceitos e contextos. Santa Maria: Ed. da UFSM, 2011.

MATHIESEN, Thomas. A sociedade espectadora: o "panóptico" de Michel Foucault revisitado. Revista Margem, São Paulo, n. 8, p.77-95, dez. 1998.

MIRZOEFF, Nicholas. What is visual culture? In: MIRZOEFF, Nicholas (Ed.). The visual culture reader. Londres: Routledge, 1998. p. 3-13.

MIRZOEFF, Nicholas. Una introducción a la cultura visual. Barcelona: Paidós Arte Y Educación, 2003.

MITCHELL, W. J. Thomas. Mostrando el ver: una crítica de la cultura visual. In: Estudios Visuales. Murcia. Centro de Documentación y Estudios Avanzados de Arte Contemporáneo, Noviembre, 2003, p.17-40.

MITCHELL, W. J. Thomas. Teoría de la imagen. Madrid, España: Ediciones Akal, 2009. 
MITCHELL, W. J. Thomas. ¿Qué quieren realmente las imágenes? México: 2014. Disponível em: http://cocompress.com/files/gimgs/WJT\%20Mitchell

OLIVEIRA, Marilda Oliveira de; PAZ, Thais Raquel da Silva. Docência em artes visuais: a cultura visual como possibilidade de produção do desejo na contemporaneidade. In: XVI ENDIPE - Encontro Nacional de Didática e Práticas de Ensino, 16., 2012, Campinas. Anais... Campinas, 2012. Disponível em:http://www.infoteca.inf.br/endipe/smarty/templates/arquivos_template/upload_arquivos/acervo/doc s/2245p.pdf

ROLNIK, Suely. Uma insólita viagem à subjetividade: fronteiras com a ética e a cultura. In: LINS, Daniel S. (Org.). Cultura e subjetividades: saberes nômades. Campinas, SP: Papirus, 1997.

SANTAELLA, Lúcia; NÖTH, Winfried. Imagem: cognição, semiótica e mídia. São Paulo: Editora lluminuras, 2001.

SANTOS, A. Cláudia. As imagens como elemento problematizador em contextos pós-modernos: por uma ontologia da educação visual. Chapecó: Programa de Pós-Graduação/Universidade Comunitária da região de Chapecó - UNOCHAPECÓ, 2015. Dissertação

SAUNDERS, Robert. A educação criadora nas artes. São Paulo: AR'TE, 1984.

SILVA, Tomaz Tadeu. O currículo como fetiche: a poética e a política do texto curricular. Belo Horizonte: Autêntica, 1999.

\section{Cláudia Aparecida dos Santos}

Doutoranda em Educação, LP4 Educação e Artes - PPGE/Universidade Federal de Santa Maria (UFSM), membro do Grupo de Estudos e Pesquisa em Arte, Educação e Cultura (GEPAEC) - UFSM, Mestre em Educação pela Universidade comunitária da região de Chapecó (UNOCHAPECO) 2015, graduada bacharel em desenho e plástica pela Universidade Federal de Santa Maria (UFSM) 2010, graduada em Artes Visuais - licenciatura plena, pela Universidade Federal de Santa Maria (UFSM), 2008. Atuei como professora de Artes Visuais na rede pública municipal nos municípios de Dom Feliciano (RS) de 2009 a 2011, e Chapecó 2011 a 2013.

Email: claudiasartes@yahoo.com.br

Currículo: http://lattes.cnpq.br/3847752613151955

Recebido em 31 de agosto de 2016 Aceito em 14 de dezembro de 2016 